\title{
Introduction à la partie statistique 2005
}

\section{Gérard Perroulaz et Xavier Tschumi Canosa}

\section{OpenEdition \\ Journals}

Édition électronique

URL : http://journals.openedition.org/aspd/436

DOI : 10.4000/aspd.436

ISSN : 1663-9669

\section{Éditeur}

Institut de hautes études internationales et du développement

\section{Édition imprimée}

Date de publication : 1 avril 2005

Pagination : 209

ISSN : 1660-5934

\section{Référence électronique}

Gérard Perroulaz et Xavier Tschumi Canosa, «Introduction à la partie statistique 2005 », Annuaire suisse de politique de développement [En ligne], 24-1 | 2005, mis en ligne le 05 mars 2010, consulté le 24 septembre 2020. URL : http://journals.openedition.org/aspd/436 ; DOI : https://doi.org/10.4000/ aspd. 436 


\section{Introduction}

A SECONDE PARTIE de l'Annuaire suisse de politique de développement ( $\left.\mathrm{n}^{\mathrm{o}} 1\right)$ fournit traditionnellement les principaux chiffres des relations de la Suisse avec les pays en développement et en transition. Trois grands groupes de relations sont retenus dans cette partie: les flux commerciaux, les flux financiers et les flux d'aide au développement.

Au vu de la diffusion d'Internet et de la disponibilité croissante de données statistiques dont chacun peut tirer profit sur ce support, cette seconde partie de l'Annuaire est présentée sous une nouvelle forme à partir de cette année :

- la première section est pensée comme un guide permettant au lecteur de retrouver sur Internet les principales informations concernant les trois groupes de flux retenus jusqu'alors dans la partie statistique de l'Annuaire;

$\checkmark$ la deuxième section offre une vue synthétique des relations de la Suisse avec les pays en développement et en transition et reprend les tableaux du chapitre 4 de la partie statistique des éditions précédentes de l'Annuaire ;

- la troisième section met en lumière certains flux caractéristiques de ces relations. Selon les choix quant aux flux à retenir, la présentation de cette section sera variable d'année en année.

La nouvelle forme de cette partie statistique marque indéniablement une rupture par rapport à celle qui était adoptée précédemment. Décider d'une telle rupture n'a pas été une tâche évidente et si ce pas a été franchi, c'est essentiellement en raison du constat que nombre de tableaux présentés jusqu'ici dans la partie statistique de l'Annuaire se trouvent actuellement tels quels, ou presque, sur Internet. En conséquence, seuls les tableaux de données qui apportent une valeur ajoutée par rapport à celles disponibles sur Internet seront désormais publiés dans la partie statistique de l'Annuaire.

Aussi le comité de rédaction de l'Annuaire serait-il reconnaissant envers les utilisateurs de la partie statistique qui le désirent de bien vouloir faire part de leurs remarques sur la nouvelle structure présentée ici, à <xavier.tschumi@iued.unige.ch>ou <gerard.perroulaz@iued.unige.ch>. 